\title{
Positron Emission Tomographic Scan Investigations of Huntington's Disease: Cerebral Metabolic Correlates of Cognitive Function
}

\author{
Stanley Berent, $\mathrm{PhD},{ }^{*} \dagger \ddagger$ Bruno Giordani, $\mathrm{PhD},{ }^{*} \ddagger$ Shirley Lehtinen, MA, ${ }^{*}$ Dorene Markel, MS, $\dagger$ \\ John B. Penney, MD, $\dagger$ H. A. Buchtel, PhD, ${ }^{*} \neq$ Simon Starosta-Rubinstein, MD, $\dagger$ Richard Hichwa, PhD, $\S$ \\ and Anne B. Young, $\mathrm{MD}, \mathrm{PhD} \dagger$
}

\begin{abstract}
Fifteen drug-free patients with early to mid-stage Huntington's disease (HD) were evaluated with positron emission tomographic (PET) scans of ${ }^{18} \mathrm{~F}$-2-fluoro-2-deoxy-D-glucose uptake and quantitative measures of neurological function, learning, memory, and general intelligence. In comparison with a group of normal volunteers, the HD patients showed lower metabolism in both caudate $(p<0.001)$ and putamen $(p<0.001)$ on PET scans. A significant and positive relationship was found between neuropsychological measures of verbal learning and memory and caudate metabolism in the patient group but not in the normal group. Visual-spatial learning did not reflect a similar pattern, but performance intelligence quotient was positively related to both caudate and putamen metabolism in the HD group. Vocabulary level was unrelated to either brain structure. Discussion focuses on these and other observed brainbehavior relationships and on the implications of these findings for general behaviors such as those involved in coping and adaptation.
\end{abstract}

Berent S, Giordani B, Lehtinen S, Markel D, Penney JB, Buchtel HA, Starosta-Rubinstein S, Hichwa R, Young $\mathrm{AB}$. Positron emission tomographic scan investigations of Huntington's disease: cerebral metabolic correlates of cognitive function. Ann Neurol 1988;23:541-546

Huntington's disease (HD) is a dominantly inherited disorder that usually starts about age 40 years and progresses over a 10- to 30-year period [16, 21]. Early neurological signs of the disease include chorea, decreased fine motor coordination, and slowed saccadic eye movements [9, 11, 23-25, 32]. Behavioral signs that occur later in the progression of the disease include dysarthria, rigidity, bradykinesia, and dystonia $[9,11,23-25,32]$.

There is substantial evidence that as $\mathrm{HD}$ develops, there is corresponding and progressive neuronal loss, increased cognitive impairment, and worsening capacity to perform the activities of daily living. Pathologically, HD is characterized by marked neuronal loss in the caudate nucleus and putamen $[5,15,30]$ but few or no cortical abnormalities [30]. The general behavioral decline in HD has been evaluated using standardized rating scales of functional capacities $[9,11$, 23-25, 31, 32]. Less is known, however, about the specific cognitive impairments that possibly subserve these more general disabilities. The documented cog- nitive impairment in $\mathrm{HD}$ appears to proceed in a regular fashion that mirrors the physiological deterioration $[6,7]$.

Until recently, there has been little opportunity to study the relationships that might exist between observed behavior and underlying physiological processes. With the advent of positron emission tomographic (PET) techniques, however, a direct comparison between behavior, metabolism, and structural integrity of the nervous system has become possible. Studies with PET have already revealed a significant reduction in caudate metabolism in patients with early $\mathrm{HD}$ who show little or no atrophy as measured structurally by computed $x$-ray tomography (CT) $[12,13,31]$. Other studies have examined patients in various stages of their illness to investigate the relationship between brain metabolism and neurological features $[13,14$, 19]. In earlier work [31], we demonstrated a relationship between metabolism and functional aspects of behavior that, it was hypothesized, would be directly related to the function of the area of the brain being
From the Departments of "Psychiatry, $\uparrow$ Neurology, and $\ddagger$ Psychology, and the $\$ \mathrm{Division}$ of Nuclear Medicine, University of Michigan, and the "Veterans Administration Medical Center, Ann Arbor, MI.
Received Sep 2, 1987, and in revised form Oct 30 and Dec 7. Accepted for publication Dec 7, 1987.

Address correspondence to Dr Berent, $480 \mathrm{Med}$ Inn Bldg, University of Michigan Hospitals, Ann Arbor, MI 48109-0840. 
imaged. Using this approach, it was possible to demonstrate that reductions in metabolism could be detected with PET before structural changes in brain could be measured using CT. We also presented observations on general behavioral efficiency and neurological signs. The present work focuses on cognitive abilities such as verbal and visual learning and seeks to relate these variables to the metabolic function in regions of brain that are known to be affected in HD.

\section{Materials and Methods}

Fifteen patients with the diagnosis of adult-onset $H D$ were scheduled for 2 days of examinations. Diagnoses were determined by family history and physical examination. Informed consent was obtained following a full explanation of the procedures to be undertaken. All studies reported here were done at least 1 month after discontinuation of any medications. During a 2-day period, each patient received a PET scan using ${ }^{18} \mathrm{~F}$-2-fluoro-2-deoxy-D-glucose $\left({ }^{18} \mathrm{~F}\right.$-FDG). In addition, each patient received a quantitative neurological examination and evaluation for functional capacity, as described previously [31], and a neuropsychological evaluation using standardized psychometric techniques.

Patients ranged in age from 25 to 60 years (mean age $=$ 40.5 years). Fourteen normal volunteers ranged from 25 to 65 years (mean age $=37.5$ years). Patients included in these studies were in stages I ( 5 patients), II (9 patients), or III (1 patient) of HD as defined by the Shoulson and Fahn scale [26]. This scale characterizes patients in terms of symptom severity, with stage I being the least severe and stage III being moderately severe.

All patients were scanned on a Cyclotron Corporation PCT 4500A tomograph (a 3-ring, 5-slice, 96-detector/ring tomograph) according to previously described techniques [31]. The spatial resolution of the scanner was $11 \mathrm{~mm}$ in the $\mathrm{x}$-y plane and $8.8 \mathrm{~mm}$ in the $\mathrm{z}$ plane. Metabolic data from each scan were analyzed by a technique described in detail elsewhere [31]. All parients were positioned in the scanner so that the slices were parallel to the canthomeatal line. Briefly, the slice corresponding to $0^{\circ}$ section, number 8 or 9 from the CT atlas of Matsui and Hirano [17], was analyzed in detail for each patient. In cases where two secrions appeared equally to approximate this slice, data were obtained on both slices and averaged. Cross-sectional histograms were obtained as follows: (1) the caudate nucleus (halfway between the rostral edge of the thalamus and the frontal cortex anterior to the ventricles); (2) the putamen (halfway between the caudate cross-section and the rostral edge of the thalamus); and (3) the middle of the thalamus. By inspection of the cross-sectional histograms, it was possible to observe the maximum glucose metabolic rate over the head of the caudate in all the normal volunteers and the HD patients. Although caudate metabolism in some of the patients was very low, there was an indication of a shoulder on the crosssectional histogram that allowed the determination of caudate metabolism at the inflection of the curve [31\}. Values of caudate, putamen, and thalamus local cerebral metabolic rate for glucose (ICMRGIc) were taken as an average of data from $1 \times 3$ pixel regions of interest (ROIs) on a $64 \times 64$ pixel matrix reconstruction of the PET scan data. Values associ-

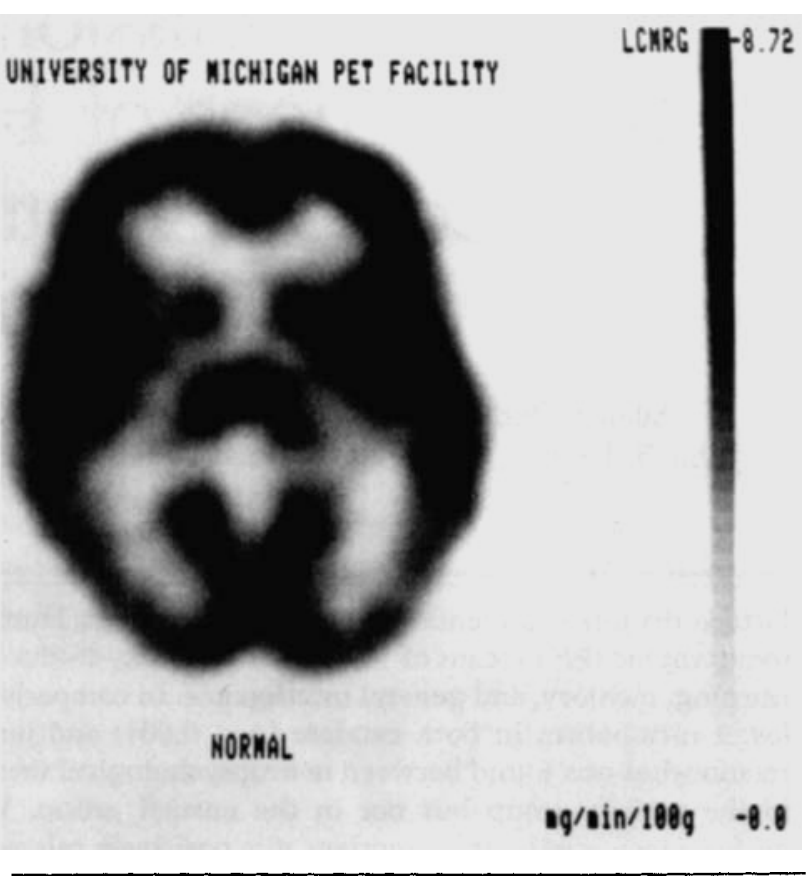

Fig 1. Positron emission tomograph of a normal volunteer.

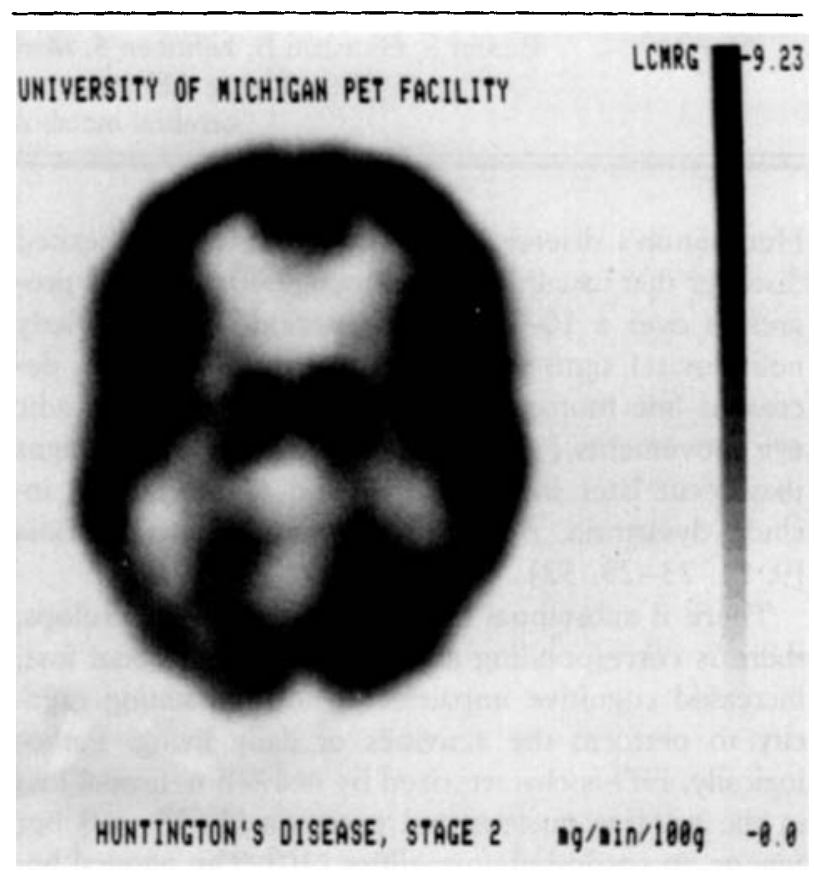

Fig 2. Positron emission tomograph of a patient with Huntington's disease, stage II.

ated with each of the ROIs were normalized to the cortical values at the same level as the ROI, as in our previous work [31]. Figures 1 and 2 show PET scans for a normal volunteer and for an HD patient, respectively. Four of the 15 patients had mild to moderate caudate atrophy on $\mathrm{CT}$ scan [31], but the method of estimating peak caudate metabolism by the histogram technique minimizes partial volume problems.

The psychological test scores used in this work were 


\begin{tabular}{|c|c|c|c|c|c|}
\hline \multirow[b]{2}{*}{ Variable } & \multicolumn{2}{|c|}{ HD Patients } & \multicolumn{2}{|c|}{$\begin{array}{l}\text { Normal } \\
\text { Subjects }\end{array}$} & \multirow[b]{2}{*}{ Significance $^{\mathrm{a}}$} \\
\hline & Mean & $(\mathrm{SD})$ & Mean & $(\mathrm{SD})$ & \\
\hline Age (yrs) & 40.5 & $(10.30)$ & 37.5 & $(13.30)$ & NS \\
\hline \multicolumn{6}{|l|}{ ICMRGIc } \\
\hline Caudate/cortex & 0.47 & $(0.19)$ & 0.91 & $(0.10)$ & $<0.01$ \\
\hline Putamen/cortex & 0.59 & $(0.21)$ & 1.05 & $(0.07)$ & $<0.01$ \\
\hline Thalamus/cortex & 1.08 & $(0.15)$ & 0.99 & $(0.11)$ & NS \\
\hline \multicolumn{6}{|l|}{ WMS } \\
\hline MQ & 94.00 & $(13.70)$ & 127.00 & $(11.50)$ & $<0.01$ \\
\hline Verbal learning (VII) & 13.17 & $(3.30)$ & 19.83 & $(1.30)$ & $<0.01$ \\
\hline Visual learning (VI) & 7.60 & $(2.80)$ & 12.80 & $(1.50)$ & $<0.01$ \\
\hline \multicolumn{6}{|l|}{ WAIS-R } \\
\hline FSIQ & 86.20 & $(10.60)$ & 116.18 & $(13.20)$ & $<0.01$ \\
\hline PIQ & 84.58 & $(10.00)$ & 113.90 & $(15.10)$ & $<0.01$ \\
\hline Vocabulary & 8.00 & $(1.50)$ & 12.08 & $(2.30)$ & $<0.01$ \\
\hline Digit symbol & 4.90 & $(1.90)$ & 11.00 & $(2.90)$ & $<0.01$ \\
\hline
\end{tabular}

aSignificance expressed as $p$ values for $t$ test of Huntington's disease patients versus normal controls.

balues of peak metabolic activity in the caudate, putamen, and thalamus were each normalized to cortical metabolism at the same level (as assessed by $1 \times 3$ pixel regions of interest on the histogram) [31].

$\mathrm{HD}=$ Huntington's disease; $\mathrm{SD}=$ standard deviation; $1 \mathrm{CMRGIc}=$ local cerebral metabolic rate for glucose; WMS $=$ Wechsler Memory Scale; WAIS-R = Wechsler Adult Intelligence Scale-Revised; FSIQ = full-scale intelligence quotient; NS = not significant.

derived from commercially available and standardized instruments and include the Wechsler Memory Scale-Form 1 (WMS) and the Wechsler Adult Intelligence Scale-Revised (WAIS-R). This work focused on aspects of learning and memory in patients with $\mathrm{HD}$. Two subtests were chosen from the WMS for specific comparisons between the $\mathrm{HD}$ patients and normal controls-immediate recall on subtest VI as an index of visual learning and subtest VII as a measure of verbal learning. The WMS summary score, $M Q$, was also completed by employing a modified but standard system [20, 29]. The Full Scale Intelligence Quotient (IQ) from the WAIS-R was also estimated using a standard prorating formula [27]. Two scales of the WAIS-R were chosen for analyses. These were the age-corrected vocabulary score and the digit symbol subtest. These scales provided an additional measure of verbal performance and visual psychomotor performance, respectively. In all cases, tests were administered in standard fashion by trained technicians who were unaware of the patient's specific clinical or PET-metabolic classification.

Data from scans, clinical evaluations, and psychometrics were entered into the University of Michigan's computer terminal system (MTS), and the system's Amdahl 5860 was used in conjunction with the investigators' laboratory microcomputers for statistical analyses. In addition to simple description, these analyses included Pearson productmoment correlations and standard $t$ tests. The continuous and normally distributed nature of the psychometrically derived data in these studies allowed the use of these parametric statistical procedures.

\section{Results}

As pointed out in previous work [31], compared with normal control subjects, the HD group had signifi- cantly lower metabolic activity of ${ }^{18}$ F-FDG in the caudate and putamen nuclei but not in the thalamus (see Figs 1 and 2 and Table 1). Although the control subjects were younger as a group than the HD patients, the difference in age was not significant. The control subjects had significantly higher general intellectual ability as measured by the WAIS-R than the HD patients. Approximately $30 \%$ of the HD patients and $80 \%$ of the normal volunteers had received education beyond the high school level. Although eighty percent of the HD patients completed at least 12 years of schooling, the control subjects had higher education levels (mean $=14.8$ years, $S D=2.2$ ) than the $\mathrm{HD}$ patients $($ mean $=12.3$ years, $\mathrm{SD}=1.9)(t=$ $3.09 ; p<0.01$ ).

Correlational relationships between PET measures and neuropsychological test results are presented in Table 2. The relationship between ${ }^{18}$ F-FDG metabolism and $\mathrm{MQ}$ was significant only for the caudate nucleus in the HD patients. Although the magnitude of the relationship in the putamen and thalamus could be considered a trend in these patients, there appeared to be no functional relationship between these areas of brain and memory in the normal volunteers.

The relationship between WMS scores and caudate metabolism was very strong for verbal (pairedassociate) learning. No significant relationship was observed between visual-spatial learning on this test (i.e., WMS) and metabolism in the basal ganglia. No significant relationship was found between the vocabulary score on the WAIS-R (a measure of general verbal ability but one that is different from that reflected in 
Table 2. Comparison of Local Cerebral Metabolic Rates for Glucose for Huntington's Disease Patients and for Normal Volunteers

\begin{tabular}{|c|c|c|c|c|}
\hline \multirow[b]{2}{*}{ Comparison } & \multicolumn{2}{|c|}{ HD Patients } & \multicolumn{2}{|c|}{ Normal Subjects } \\
\hline & $r$ & $p$ & $r$ & $p$ \\
\hline $\begin{array}{l}\text { Caudate to } \\
\text { WMS, MQ } \\
\text { Verbal (VII) } \\
\text { Visual (VI) } \\
\text { FSIQ } \\
\text { PIQ } \\
\text { Vocabulary } \\
\text { Digit Symbol }\end{array}$ & $\begin{array}{l}+0.67 \\
+0.73 \\
-0.04 \\
+0.46 \\
+0.70 \\
+0.19 \\
+0.79\end{array}$ & $\begin{array}{l}<0.01 \\
<0.01 \\
\text { NS } \\
\text { NS } \\
<0.05 \\
\text { NS } \\
<0.01\end{array}$ & $\begin{array}{l}-0.07 \\
-0.38 \\
+0.39 \\
-0.01 \\
-0.12 \\
-0.31 \\
-0.45\end{array}$ & $\begin{array}{l}\text { NS } \\
\text { NS } \\
\text { NS } \\
\text { NS } \\
\text { NS } \\
\text { NS } \\
\text { NS }(0.14)\end{array}$ \\
\hline $\begin{array}{l}\text { Putamen to } \\
\text { WMS, MQ } \\
\text { Verbal (VII) } \\
\text { Visual (VI) } \\
\text { FSIQ } \\
\text { PIQ } \\
\text { Vocabulary } \\
\text { Digit Symbol }\end{array}$ & $\begin{array}{l}+0.50 \\
+0.50 \\
+0.02 \\
+0.38 \\
+0.66 \\
+0.30 \\
+0.85\end{array}$ & $\begin{array}{l}\text { NS }(0.07) \\
\text { NS }(0.06) \\
\text { NS } \\
\text { NS } \\
<0.05 \\
\text { NS } \\
<0.01\end{array}$ & $\begin{array}{l}-0.13 \\
-0.48 \\
+0.28 \\
-0.10 \\
-0.35 \\
-0.12 \\
-0.68\end{array}$ & $\begin{array}{l}\text { NS } \\
\text { NS }(0.11) \\
\text { NS } \\
\text { NS } \\
\text { NS } \\
\text { NS } \\
<0.01\end{array}$ \\
\hline $\begin{array}{l}\text { Thalamus to } \\
\text { WMS, MQ } \\
\text { Verbal (VII) } \\
\text { Visual (VI) } \\
\text { FSIQ } \\
\text { PIQ } \\
\text { Vocabulary } \\
\text { Digit Symbol }\end{array}$ & $\begin{array}{l}+0.41 \\
+0.47 \\
+0.20 \\
+0.33 \\
+0.06 \\
+0.02 \\
+0.02\end{array}$ & $\begin{array}{l}\text { NS } \\
\text { NS }(0.09) \\
\text { NS } \\
\text { NS } \\
\text { NS } \\
\text { NS } \\
\text { NS }\end{array}$ & $\begin{array}{l}-0.16 \\
+0.05 \\
-0.53 \\
-0.26 \\
-0.25 \\
+0.18 \\
-0.07\end{array}$ & $\begin{array}{l}\text { NS } \\
\text { NS } \\
\text { NS }(0.07) \\
\text { NS } \\
\text { NS } \\
\text { NS } \\
\text { NS }\end{array}$ \\
\hline $\begin{array}{l}\text { Caudate to } \\
\text { Putamen }\end{array}$ & +0.91 & $<0.01$ & +0.70 & $<0.01$ \\
\hline $\begin{array}{l}\text { Caudate to } \\
\text { Thalamus }\end{array}$ & -0.21 & NS & -0.41 & NS \\
\hline $\begin{array}{l}\text { Putamen to } \\
\text { Thalamus }\end{array}$ & -0.32 & NS & -0.16 & NS \\
\hline
\end{tabular}

$r=$ Pearson product-moment correlation coefficient; $p=$ signifcance level; NS = not significant; WMS = Wechsler Memory Scale; WMS FSIQ $=$ full-scale intelligence quotient.

the WMS) and metabolism in these same areas of brain.

A significant correlation was found between both normalized caudate and putamen ICMRGlc and performance on the digit symbol subtest of the WAIS-R. For the putamen, this relationship held for the normal subjects as well as the HD patients. However, the nature of the relationship appeared to be quite different for the two groups. In HD patients there was a positive relationship between metabolism and accurate performance on this test, but in normal subjects there was an inverse relationship (i.e., higher relative metabolism was associated with poorer performance).

Table 3 presents additional relationships between quantitative neurological and psychometric observations.

\section{Discussion}

These findings are consistent with the hypothesis that cognitive impairment in $\mathrm{HD}$ reflects functional deteri-
Table 3. Correlational Relationships between Bebavioral Measures-Quantitative Neurological and Psychometric

\begin{tabular}{lll}
\hline Comparison & $r_{\mathrm{x}, \mathrm{y}}$ & $p$ \\
\hline Resting Chorea to & & \\
Verbal Learning (VII) & -0.53 & $<0.05$ \\
Visual Learning (VI) & +0.02 & $\mathrm{NS}$ \\
WAIS-R, FSIQ & -0.02 & $\mathrm{NS}$ \\
Vocabulary & +0.07 & $\mathrm{NS}$ \\
Digit Symbol & -0.68 & $<0.01$ \\
Total Functional Capacity to & & \\
Verbal Learning (VII) & +0.67 & $<0.01$ \\
Visual Learning (VI) & -0.09 & $\mathrm{NS}$ \\
WAIS-R, FSIQ & +0.37 & $\mathrm{NS}$ \\
Vocabulary & +0.23 & $\mathrm{NS}$ \\
Digit Symbol & +0.75 & $<0.01$ \\
Rapid Alternating Movement to & & \\
Verbal Learning (VII) & -0.58 & $<0.05$ \\
Visual Learning (VI) & -0.20 & $\mathrm{NS}$ \\
WAIS-R, FSIQ & -0.37 & $\mathrm{NS}$ \\
Vocabulary & -0.21 & $\mathrm{NS}$ \\
Digit Symbol & -0.76 & $<0.01$ \\
\hline
\end{tabular}

$r=$ Pearson product-moment correlation coefficient; $p=$ signifi cance level; NS = not significant; WAIS-R $=$ Wechsler Adult Intelligence Scale-Revised; FSIQ = full-scale intelligence quotient.

oration of the neuroanatomical structures that subserve the affected abilities. The findings are more complex in their implications than they may at first seem, however. To the extent that these correlational observations reflect actual structural changes, they suggest specific, as well as general, effects of disease progression in HD. The HD patients as a group functioned below normal on all cognitive measures (in comparison with the normal control subjects in this study and in relation to published norms for the standardized tests). At the same time, different functional relationships appeared to exist between the structures of the brain that are affected in HD and the various abilities as measured here. For instance, the degree of hypometabolism of the caudate was found to have a strong correlation with performance on the verbal learning task but not with performance on the visual learning task. Furthermore, this relationship was specific to this structure of the basal ganglia, and no such relationship was evident for the thalamus or even the putamen. The absence of a significant relationship between the putamen and task performance is especially intriguing because metabolism itself was highly correlated between the caudate and the putamen. One might anticipate that they would both correlate with behavioral function, or dysfunction, but they do not.

If it is true that both general and specific abilities are adversely affected in HD, one might speculate that cortical, as well as subcortical, regions of brain are involved. From a neuropsychological point of view, Seidenberg and associates [22] have shown that general intelligence as measured by the WAIS-R corre- 
lates very highly with basic cognitive abilities, as reflected in tasks such as the Halstead Test Battery. Such correlations in functional aspects of behavior could sensitively reflect functional connections that exist between the cortex and subcortical structures. From a direct functional metabolic point of view, Foster and associates [10] and Berent and associates [2] have presented data that support the hypothesis of cortical hypometabolism in subcortical dementia (progressive supranuclear palsy). Whether by way of structural changes or as a reflection of disorder on a functional level, it may be that diseased subcortical regions adversely affect cortical efficiency in these HD patients. It should be said, however, that whereas a disturbance of higher cortical functions might be invoked to explain the impairment of general. intellectual ability in the population under study, subcortical regions alone can probably account for disorders in many specific cognitive functions.

The relationship between verbal learning and hypometabolism in the caudate nucleus was very specific. From a cognitive perspective, the abilities involved were not language or intelligence in general, since neither vocabulary level nor estimated full-scale IQ was found to show statistically significant correlations to regions of the basal ganglia. The finding was also specific to the $\mathrm{HD}$ group; no similar correlation was observed in the normal control group. Because verbal learning was found to correlate highly with other signs and symptoms of HD (e.g., decline in total functional capacity), one could query the role of this important cognitive ability (i.e., verbal learning) in these phenomena (see Table 3). There is an intimate relationship between basic cognitive abilities such as verbal learning and more complex behaviors such as coping and adaptation $\{1\}$. Such interactions may be reflected in the relationships that were observed between measures of functional capacity, choreic movements, and verbal acquisition. It is especially interesting that visual learning, and even estimated full-scale IQ, failed to correlate with any of these measures-functional capacity, chorea, or verbal learning-whereas each of the measures was significantly correlated with hypometabolism of the basal ganglia. One could speculate that a primary disability in coping and adaptation, and even in general behavioral efficiency, is based on impairment of the specific kinds of verbal ability measured in these patients.

Depression and other behavioral disturbances are known to manifest in HD. These behaviors can also adversely affect performance on tasks such as those tested here. All patients were subjectively judged by the examiner to be cooperative and motivated to participate in the studies; however, there was a lack of formal quantified measurement of affect. Also, a difference was observed between the HD and normal groups in terms of education. The generally lower performance of the HD patients in comparison with the normal subjects could theoretically be explained on the basis of differences in education or motivation, but such factors would seem not to explain easily the correlational findings that represent the primary focus of this work. Future effort will, nevertheless, be needed to approach these intervening variables directly.

We recently presented data indicating that ${ }^{18} \mathrm{~F}$-FDG hypometabolism in cortical structures (e.g., the temporal lobes), as opposed to hypermetabolism, is associated with impaired cognitive ability [4]. In this work also, it was relative hypometabolism in the regions of interest that was associated with lowered performance. However, the observed relationships differed between the HD and normal groups. There was no significant correlation between specific cognitive abilities and brain metabolism in the normal group. This was in contrast to some very strong relationships in the HD patients. Like the HD patients, the normal subjects did evidence a strong correlation between ${ }^{18} \mathrm{~F}$-FDG metabolism in the caudate and in the putamen, but lacked such a relationship between caudate and thalamus or putamen and thalamus. It is interesting that in the one instance of a statistically significant relationship in the normal group- ${ }^{18} \mathrm{~F}-\mathrm{FDG}$ metabolism in the putamen and performance on the Digit Symbol subtest of the WAIS-R-the relationship was inverse and opposite to that found in the HD group. In the HD patients, relative hypometabolism of the putamen was found to correlate with less accurate performance on this subtest, whereas in the normal subjects better performance was related to relative hypometabolism in the putamen. Could it be that normal functional relationships between cortical and subcortical regions of brain become distupted in a disease such as HD? To answer this question, it will be necessary to increase our understanding of the functional relationships that might exist between structures in the human brain not only under abnormal disease conditions, but in the normal state as well.

This work was supported in part by National Institutes of Health grant NS 15655 .

We wish to thank the staff of the University of Michigan Cyclotron/ P.E.T. Eacility in the Division of Nuclear Medicine.

\section{References}

1. Berent S: Psychopathology and other behavioral considerations in clinical neuropsychology. In Filskov S, Boll TJ (eds): Handbook of Clinical Neuropsychology, Vol 2. New York, Wiley, 1986

2. Berent S, Foster NL, Gilman S, Hichwa R: Pacterns of cortical ${ }^{18} \mathrm{~F}-\mathrm{FDG}$ metabolism in Alzheimer's and progressive supranuclear palsy patients are related to the type of cognitive impairments. Neurology 37:172, 1987

3. Berent $\mathrm{S}$, Giordani B, Young AB, et al: Positron emission to- 
mography (PET) of ${ }^{18} \mathrm{~F}$-2-fluoro-2-deoxy-D-glucose $\left({ }^{18} \mathrm{FDG}\right)$ uptake in the area of the caudate nucleus of patients with Huntington's disease: findings with the Wechsler Memory Scale. The International Neuropsychological Society Bulletin, November, 1984, p S

4. Berent S, Sackellares JC, Abou-Khalil B, et al: PET studies of cerebral glucose metabolic activity in temporal lobe epilepsy: the functional implications of lateralized hypometabolism. Neurology 36:336, 1986

5. Bruyn GW: Huntington's chorea: historical, clinical and laboratory synopsis. In Vinkin P, Bruyn GW (eds): Handbook of Clinical Neurology, Vol 6. Amsterdam, Elsevier, 1968, pp 298-378

6. Butters N, Sax D, Montgomery K, Tarlow S: Comparison of the neuropsychological deficits associated with early and advanced Huntington's disease. Arch Neurol 35:585-589, 1978

7. Caine ED, Ebert M, Weingartner $\mathrm{H}$ : An outline for the analysis of dementia: the memory disorder of Huntington's disease. Neurology 27:1087-1092, 1977

8. Dom R, Malfroid M, Baro F: Neuropathology of Huntington's chorea: studies of the ventrobasal complex of the thalamus. Neurology 26:64-68, 1976

9. Folstein SE, Jenson B, Leigh FJ, Folstein MF: The measurement of abnormal movement: methods developed for Huntington's disease. Neurobehav Toxicol Teratol 5:605-609, 1983

10. Foster NL, Gilman S, Berent S, Hichwa R: Distinctive patterns of cerebral cortical glucose metabolism in progressive supranuclear palsy and Alzheimer's disease studied with positron emission tomography. Neurology 36:338, 1986

11. Hayden M: Huntington's Chorea. Berlin, Springer Verlag, 1981

12. Hayden MR, Martin WRW, Stoessl J, et al: The combined use of positron emission tomography (PET) and DNA polymorphisms in preclinical detection of Huntington's disease. Am J Hum Genet 37 (suppl 1):A58, 1985

13. Kuhl DE, Metter EJ, Riege WH, Markham CH: Patterns of cerebral glucose utilization in Parkinson's disease and Huntington's disease. Ann Neurol 15:\$119-\$125, 1984

14. Kuhl DE, Phelps ME, Markham CH, et al: Cerebral metabolism and atrophy in Huntington's disease determined by ${ }^{18}$ FDG and computed tomographic scan. Ann Neurol 12:425-434, 1982

15. Lange HW: Quantitative changes of telencephalon, diencephalon and mesencephaion in Huntington's chorea, postencephalitic and idiopathic parkinsonism. Verth Anat Ges 75:923-925, 1981

16. Martin JB: Huntington's disease: new approaches to an old problem. Neurology 34:1059-1072, 1984
17. Matsui T, Hirano A: An Atlas of the Human Brain for Computerized Tomography. Tokyo, Igaku-Shoin, 1978

18. Phelps ME, Huang SC, Hoffman EJ, et al: Tomographic measurement of local cerebral glucose metabolic rate in humans with (F-18)2-fluoro-2-deoxy-D-glucose: validation of method. Ann Neurol 6:371-388, 1979

19. Phelps ME, Mazziotta JC: Positron emission tomography: human brain function and biochemistry. Science 228:799-809, 1985

20. Power EG, Logue PE, McCarty SM, et al: Inter-rater reliability of the Russell revision of the Wechsler Memory Scale: an attempt to clarify some ambiguities in scoring. $\mathrm{J}$ Clin Neuropsychol 1:343-345, 1979

21. Sanberg PR, Coyle JT: Scientific approaches to Huntington's disease. CRC Crit Rev Clin Neurobiol 1:1-44, 1984

22. Seidenberg M, Giordani B, Berent S, Boll TJ: IQ level and performance on the Halstead Neuropsychological Test Battery for Children. J Consult Clin Psychol 51:406-413, 1984

23. Shoulson I: Huntington's disease: functional capacities in patients treated with neuroleptic and antidepressant drugs. Neurology 31:1333-1335, 1981

24. Shoulson I: Care of patients and families with Huntington's disease. In Marsden CD, Fahn S (eds): Movement Disorders. International Medical Review Series. London, Butterworth, 1982, pp 277-290

25. Shoulson I: Huntington's disease: a decade of progress. Neurol Clin 2:515-526, 1984

26. Shoulson I, Fahn S: Huntington's disease: clinical care and evaluation. Neurology 29:1-3, 1979

27. Silverstein AB: Two- and four-subtest short forms of the WAIS-R. J Consult Clin Psychol 50:415-418, 1982

28. Sokoloff L: The relationship between function and energy metabolism: its use in the localization of functional activity in the nervous system. Neurosci Res Program Bull 19:159-210, 1981

29. Sweet JJ, Wysocki JJ: Improving score reliability of the Wechsler Memory Scale: a pilot study. Clin Neuropsychol 4:159-161, 1982

30. Von Sattel JP, Ferrante RJ, Stevens TJ, et al: Neuropathologic classification of Huntington's disease. J Neuropathol Exp Neurol 44:559-577, 1985

31. Young AB, Penney JB, Starosta-Rubinstein S, et al: PET scan investigations of Huntington's disease: cerebral metabolic correlates of neurological features and functional decline. Ann Neurol 20:296-303, 1986

32. Young AB, Shoulson I, Penney JB, et al: Huntington's disease in Venezuela: neurological features and functional decline. Neurology 36:244-249, 1986 